\title{
Chapter 7 \\ Dark Matters: The Effects of Artificial \\ Lighting on Bats
}

\author{
E.G. Rowse, D. Lewanzik, E.L. Stone, S. Harris and G. Jones
}

\begin{abstract}
While artificial lighting is a major component of global change, its biological impacts have only recently been recognised. Artificial lighting attracts and repels animals in taxon-specific ways and affects physiological processes. Being nocturnal, bats are likely to be strongly affected by artificial lighting. Moreover, many species of bats are insectivorous, and insects are also strongly influenced by lighting. Lighting technologies are changing rapidly, with the use of light-emitting diode (LED) lamps increasing. Impacts on bats and their prey depend on the light spectra produced by street lights; ultraviolet (UV) wavelengths attract more insects and consequently insectivorous bats. Bat responses to lighting are species-specific and reflect differences in flight morphology and performance; fast-flying aerial hawking species frequently feed around street lights, whereas relatively slowflying bats that forage in more confined spaces are often light-averse. Both highpressure sodium and LED lights reduce commuting activity by clutter-tolerant bats of the genera Myotis and Rhinolophus, and these bats still avoided LED lights when dimmed. Light-induced reductions in the activity of frugivorous bats may affect ecosystem services by reducing dispersal of the seeds of pioneer plants and hence reforestation. Rapid changes in street lighting offer the potential to explore
\end{abstract}

E.G. Rowse and D. Lewanzik: Equal contributors.

E.G. Rowse · E.L. Stone $\cdot$ S. Harris · G. Jones $(\bowtie)$

School of Life Sciences, University of Bristol, Bristol, UK

e-mail: Gareth.Jones@bristol.ac.uk

D. Lewanzik

Department of Evolutionary Ecology, Leibniz Institute for Zoo and Wildlife Research,

Berlin, Germany

D. Lewanzik

Animal Behaviour, Freie Universität Berlin, Berlin, Germany

(C) The Author(s) 2016 
mitigation methods such as part-night lighting (PNL), dimming, directed lighting, and motion-sensitive lighting that may have beneficial consequences for lightaverse bat species.

\subsection{Introduction}

Anthropogenic change is altering ecosystems at unprecedented rates and humans now dominate most ecosystems (Vitousek et al. 1997; McDonald 2008). Urbanisation in particular has major impacts on bat activity and abundance (Jung and Threlfall 2016), and one aspect of global change that occurs predominately, but not exclusively, in urban areas is increased artificial light at night. Almost a fifth of the global land area was affected by light pollution in 2001 (Cinzano et al. 2001). Although night-time brightness generally increased in Europe between 1995 and 2010, regional patterns are complex, with some localised declines (Bennie et al. 2014). However, the biological impacts of light pollution have only recently been recognised (Longcore and Rich 2004).

Being nocturnal, bats are likely to be affected by light pollution. In this chapter, we review the types of artificial light that bats experience, describe how light pollution has become more widespread in recent years, show how technological changes may lead to significant reductions in light pollution and describe some of the physiological consequences of light pollution that may be relevant to bats. We then discuss how artificial lighting affects the insect prey of bats, and why some bats may benefit from the growth in artificial lighting, whereas others are affected detrimentally. After highlighting some aspects of bat vision, we describe the shift from observational to experimental studies of how bats respond to lighting. Finally, we identify some of the major knowledge gaps and suggest priorities for future research on the effects of artificial lighting on bats.

\subsection{Types of Artificial Light}

The electromagnetic spectrum encompasses radiation with wavelengths ranging from less than a nanometre (gamma rays) to a kilometre (radio waves) (Campbell 2011). While humans perceive wavelengths between 400 and $700 \mathrm{~nm}$ as 'visible light' (Purves and Lotto 2003), birds, fish and invertebrates can detect light in the ultraviolet (UV) range $(10-400 \mathrm{~nm})$. Recent work suggests that UV sensitivity may be widespread among mammals (Douglas and Jeffery 2014), and snakes and beetles can detect spectral emissions in the infrared range (700-1000 nm) (Schmitz and Bleckmann 1998; Land and Nilsson 2012).

Artificial lighting has infiltrated all aspects of human life both indoors and outside (Gaston et al. 2012). Here, we focus on street lighting because of its universal use and potential for ecological impacts (Gaston et al. 2012). Different types of street light have distinct spectral signatures (Fig. 7.1); their primary emissions 

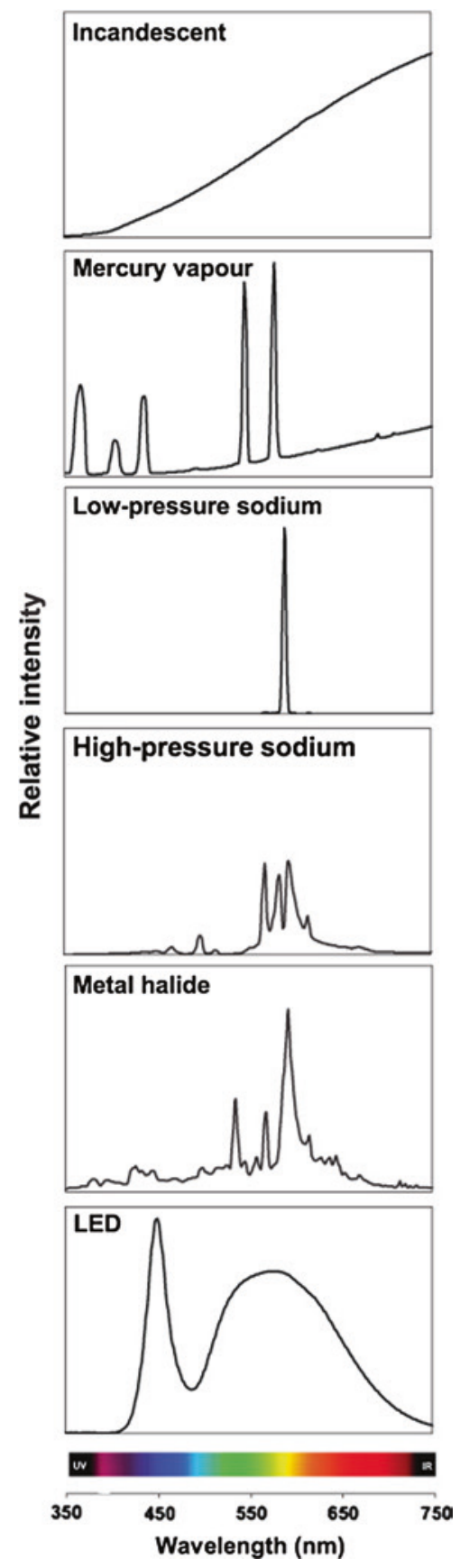

Fig. 7.1 The spectral content of different light types varies considerably. The spectral composition of common lighting technologies is shown. From Gaston et al. (2013) 
depend on the type of reactive material or coating in the lamps (Buchanan 2006). Incandescent lamps, developed by Thomas Edison in 1880, mainly emit long wavelengths with a maximum intensity between 900 and $1050 \mathrm{~nm}$ (Elvidge et al. 2010). Despite improvements such as the quartz halogen lamp, which uses an inert gas to preserve the tungsten filament, incandescent lamps are still relatively inefficient because their emissions are predominantly near the infrared spectrum and so largely invisible to humans (Elvidge et al. 2010).

Gas discharge lamps, developed by the mid-twentieth century, produce light by passing electric arcs through gas-filled bulbs (Elvidge et al. 2010). These are further classified as low-pressure discharge and high-intensity discharge (HID) lamps (Elvidge et al. 2010). Low-pressure discharge lamps include the compact fluorescent lamp (CFL) and low-pressure sodium (LPS) lamps. Fluorescent lamps produce distinct emission peaks, which combine to emit a 'white' light (Royal Commission on Environmental Pollution 2009; Elvidge et al. 2010), whereas LPS lamps have a narrow spectral signature, emitting monochromatic orange light with a peak intensity of $589 \mathrm{~nm}$ (Fig. 7.1) (Rydell 2006; Elvidge et al. 2010).

HID lamps include high-pressure mercury vapour (HPMV) lamps, which produce a bluish-white light, and high-pressure sodium (HPS) and metal halide lamps that have broader spectral emissions (Fig. 7.1) (Davies et al. 2013). Emissions from HPMV lamps extend into the UV range (Rydell 2006; Elvidge et al. 2010), whereas HPS lamps emit yellow-orange light and metal halide lamps 'white' light (Royal Commission on Environmental Pollution 2009; Davies et al. 2013; Gaston et al. 2013). The colour rendering index (CRI) compares how accurately a light source replicates the full range of colours of an object viewed in natural light on a scale of 0-100, where 100 is equivalent to natural light (Schubert and Kim 2005; Elvidge et al. 2010; Davies et al. 2013). HPS lamps typically have a CRI between 7 and 32, whereas metal halide lamps have a CRI ranging from 64 to 100, reflecting their ability to render colour more suited for human vision (Elvidge et al. 2010; Gaston et al. 2012).

Gas discharge lamps replaced incandescent lamps because of their energy efficiency and improved longevity (Schubert and Kim 2005), and LPS (44\%) and HPS (41\%) lamps came to dominate street lighting in the UK (Royal Commission on Environmental Pollution 2009) and elsewhere. The luminous efficacy (LE) (amount of light produced per watt of electricity) of gas discharge lamps is five times higher than incandescent lamps (Schubert and Kim 2005; Elvidge et al. 2010). However, with pressure to reduce energy use and $\mathrm{CO}_{2}$ emissions, the lighting industry is now turning to light-emitting diodes (LEDs) (Elvidge et al. 2010; Gaston et al. 2012). LEDs have broad spectral signatures, typically 400-700 nm, with very few emissions in the UV range (Elvidge et al. 2010). This is achieved mainly through the use of cerium-doped yttrium aluminium garnet (YAG:Ce) phosphors with a gallium nitride $(\mathrm{GaN})$ which converts monochromatic blue to 'white' light. However, more recently LEDs are able to produce light by combining multiple monochromatic sources (red, green and blue), which allows for greater control over spectral emissions (Narendran et al. 2004; Gaston et al. 2012, 2013; Davies et al. 2013). LED lamps have comparable CRI scores to metal 
halide lamps (65-100) (Elvidge et al. 2010) but benefit from lower running costs (Gaston et al. 2012); low energy consumption (Elvidge et al. 2010); controllability of spectral, temporal and intensity of emissions; reduced $\mathrm{CO}_{2}$ emissions (Hölker et al. 2010a); and smart lighting capabilities that enable dimming in response to weather, traffic and lunar conditions (Bennie et al. 2014).

\subsection{The Growth of Light Pollution}

Light pollution is defined as the changing of natural light levels in nocturnal landscapes (nightscapes) through artificial lighting sources (Falchi et al. 2011; Kyba and Hölker 2013). Here, we focus on ecological light pollution, i.e. the direct ecological effects of light as opposed to astronomical light pollution, which describes the light that disrupts viewing of stars and other celestial matter (Longcore and Rich 2004). Ecological light pollution can be caused by glare (extreme contrasts between bright and dark areas), over-illumination, light clutter (unnecessary numbers of light sources), light trespass (unwanted light) and skyglow, where artificial light is directed towards the sky, scattered by atmospheric molecules and reflected back to earth (Royal Commission on Environmental Pollution 2009; Gaston et al. 2012; Kyba and Hölker 2013).

Artificial lighting has increased as a result of urbanisation, population growth, economic development and advances in lighting technologies and provides numerous economic, commercial, recreational and security benefits (Riegel 1973; Hölker et al. 2010a; Davies et al. 2012). However, light pollution is now of global concern: the accelerated use of electric lighting, growing at $6 \%$ per year, has escalated light pollution to threat status (Hölker et al. 2010a, b). Satellite images suggest that $19 \%$ of the global land surface surpassed the threshold for acceptable lighting levels (Cinzano et al. 2001). However, satellites are unable to capture all illumination from light sources (Bennie et al. 2014). While light pollution is currently more apparent in developed nations (Fig. 7.2), projected increases in industrial and urban growth suggest that light pollution will become more spatially heterogeneous both locally and regionally (Cinzano et al. 2001; Gaston et al. 2012; Hölker et al. 2010b; Bennie et al. 2014).

In the UK, street lighting consumes approximately 114 Twh of energy annually (International Energy Agency 2006) and is growing at $3 \%$ per annum (Royal Commission on Environmental Pollution 2009). The number of lighting installations is increasing (Gaston et al. 2012), and the change in emissions due to increased use of broad spectrum technologies is also likely to affect light pollution as these sources emit higher levels of blue light. This scatters more into the atmosphere than green or red light, ultimately making a bigger contribution to skyglow (Benenson et al. 2002; Falchi et al. 2011; Kyba and Hölker 2013). The growth in light pollution will be further exacerbated because, as LEDs become cheaper, non-essential uses, such as advertising and architectural lighting, may increase (Schubert and Kim 2005). 


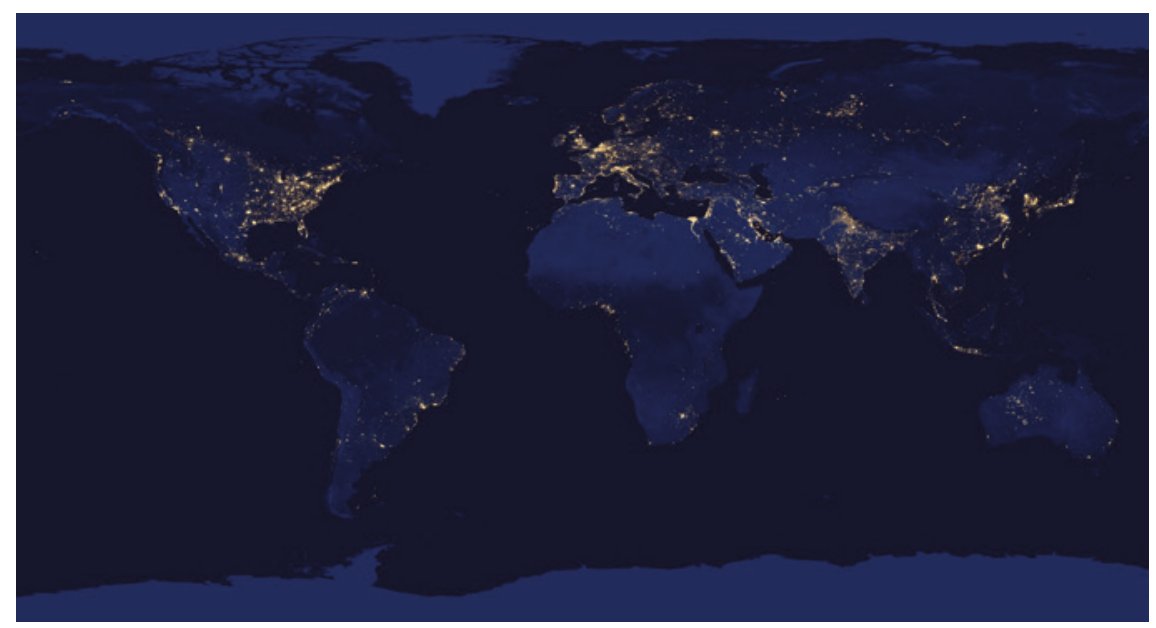

Fig. 7.2 Artificial lighting is currently most widespread in the developed world. Global use of lighting at night in 2000. From NASA Earth Observatory/NOAA NGDC (2012)

\subsection{Projected Changes in Technology}

International lighting policies are prioritising energy-efficient technologies to reduce costs and $\mathrm{CO}_{2}$ emissions. The European Ecodesign Directive, for instance, encourages moves from energy-intensive technologies such as incandescent, LPS and HPMV lamps (Hölker et al. 2010a) to 'whiter' lighting with higher colour rendering capabilities (Gaston et al. 2012). This may reduce $\mathrm{CO}_{2}$ emissions in the EU by as much as $42 \mathrm{Mt}$ per year. A number of pilot studies in cities around the world (including Adelaide, Hong Kong, London, Mumbai, New York, Sydney and Toronto) have compared LED lamps against existing lighting technologies. After a three-year trial, the City of Sydney Council agreed to switch to LEDs on 6500 outdoor lights due to their reduced energy consumption, cost-effectiveness and improved illuminance (The Climate Group 2014).

Future research will focus on increasing the efficiencies of LEDs: the LE of a LED is $60-90 \mathrm{~lm} / \mathrm{W}$, compared to $80-120 \mathrm{~lm} / \mathrm{W}$ for HPS lamps (California Lighting Technology Center 2010). More effective ways of producing light are also being investigated, such as combining multiple monochromatic sources as opposed to using phosphors: this will increase control over spectral emissions (Schubert and Kim 2005; Gaston et al. 2012).

\subsection{The Biological Effects of Light Pollution}

The number of studies revealing negative consequences of artificial night lighting on a multitude of both diurnal and nocturnal vertebrates and invertebrates is increasing rapidly (reviewed in Rich and Longcore 2006). Most negative effects 
are due to the disruption of natural circadian and circannual cycles, which in turn can affect a whole range of species interactions, physiological processes and behaviours.

\subsubsection{Impacts of Light Pollution on Intra- and Inter-specific Competition}

Light-induced changes in circadian activity patterns can alter competition both within species (e.g. for mates) and between species (e.g. interference and exploitation competition). These are best documented for birds. For instance, early singing may be a signal of male quality in songbirds and increases the rate of extra-pair copulations, which are usually higher in older males. In territories affected by artificial light, males of several songbird species start singing earlier at dawn and thereby gain access to about twice as many extra-pair mates (Kempenaers et al. 2010; Nordt and Klenke 2013; Dominoni et al. 2014). The effect of artificial light on paternity gain is even stronger in yearlings than in adults, and so street lights might result in maladaptive mate choice of females by artificially increasing the extra-pair success of yearlings (Kempenaers et al. 2010). Whether similar maladaptive effects occur with nocturnal species is less clear.

Artificial light can affect niche partitioning by extending the activity of diurnal species, bringing them into inter-specific competition with nocturnal species (Longcore and Rich 2004; Rich and Longcore 2006). The scissor-tailed flycatcher Tyrannus forficatus, for example, will catch insects at street lights until at least $3 \mathrm{~h}$ after sunset (Frey 1993); this may increase exploitation and interference competition with insectivorous bats. Light pollution may also cause inter-specific competition between bats, with light-sensitive bat species excluded from illuminated resources exploited by light-tolerant species (Arlettaz et al. 2000).

\subsubsection{Effects of Artificial Light on Physiological Homeostasis}

Light-induced changes in circadian rhythms may induce physiological aberrations. For instance, exposure of captive mice to light at night disrupts metabolic signals, leading to increased body mass and decreased glucose tolerance (Fonken et al. 2010). Dim night-time light can also impair learning and memory, affect stress hormone levels, compromise immune function and cause depressive-like behaviour in rodents (Bedrosian et al. 2011, 2013; Fonken et al. 2012). In humans, depression, obesity and cancer risk relate to light pollution and associated disruptions of the circadian system (Fonken and Nelson 2011; Kronfeld-Schor and Einat 2012; Haim and Portnov 2013). 
Light pollution can also result in a decoupling of seasonal behaviours and physiological adaptations from the optimal time of year. So, for instance, reproduction might be desynchronised from peak food availability; even very low light levels at night advance avian reproduction (Dominoni et al. 2013) so that birds breed earlier close to street lights than in darker territories (Kempenaers et al. 2010). Light-induced decoupling can even reverse an animal's seasonal phenotype, so that it exhibits a long-day phenotype in winter and vice versa. In sheep, $1 \mathrm{~h}$ of light during the dark phase is enough to mimic a long-day during short-day conditions (Chemineau et al. 1992). Also in primates, artificial light at night can induce a long-day phenotype; these animals had higher core body temperatures, showed less locomotor activity during the nocturnal activity period and had fainter torpor bouts compared with short-day photoperiod acclimated animals (Le Tallec et al. 2013). Voles that experienced light interference at night showed reduced winter acclimatisation of their thermoregulatory system to such a degree that they reduced heat production and died under winter field conditions (Haim et al. 2004, 2005). Thus, light pollution may have deleterious impacts on survival when animals expend too much energy during winter (Haim et al. 2004): this may be relevant for hibernating bats.

\subsubsection{Interference of Light Pollution with Nocturnal Navigation}

A well-documented effect of light pollution not mediated through circadian rhythms is the impact on movement decisions of visually orienting animals. Nesting attempts of female sea turtles are disrupted by artificial light, and light attracts or confuses the hatchlings, rendering them more vulnerable to predation, exhaustion and dehydration (Salmon 2006; Perry et al. 2008; Berry et al. 2013).

Birds migrating at night often approach bright lights instead of following their normal migration route, possibly because the light interferes with their magnetic compass (Poot et al. 2008). Birds may also be trapped within the sphere of light, milling around illuminated objects until they die through collisions or exhaustion (Gauthreaux and Belser 2006; Montevecchi 2006; Spoelstra and Visser 2014). This may have relevance to bats, which also use magnetic compasses for navigation (Holland et al. 2006).

Similarly many insects, particularly moths (Lepidoptera), use artificial lights rather than the moon for orientation and die of exhaustion when circling a lamp or following a collision with the hot cover. Artificial light also provokes a 'dazzling effect': many insects become immobilised when approaching a lamp and rest on the ground or in vegetation, becoming easy prey (Eisenbeis 2006). Light pollution may even be a driver of an insect biodiversity crisis (Conrad et al. 2006). The 'vacuum cleaner' effect, i.e. the long-distance attraction of light-susceptible species to lamps, removes large numbers of insects from the ecosystem, even 
resulting in local extinctions. This flight-to-light behaviour strongly depends on spectral output of the lighting: white HPMV lamps have a high UV proportion of their spectrum, and so four times as many moths are captured at HPMV lights compared to yellow/orange HPS lights (Eisenbeis 2006). Warm-white and cool-white LED lights induce less flight-to-light behaviour than HPS lights (Huemer et al. 2010; Eisenbeis and Eick 2011), and the virtually monochromatic deep-orange LPS lights are least attractive to insects (Rydell 1992; Blake et al. 1994; Eisenbeis 2006; Frank 2006).

Several spiders, amphibians, reptiles, birds and bats focus their foraging on insects accumulated at street lights (Rich and Longcore 2006). For bats, this can also be advantageous because artificial light disrupts the evasive behaviour of most nocturnal Lepidoptera, rendering them more vulnerable to bat attacks (Svensson and Rydell 1998; Acharya and Fenton 1999).

\subsection{Bat Vision}

Vision is important in the lives of many bats; see reviews in Suthers (1970), Altringham and Fenton (2003) and Eklöf (2003). A number of species rely on vision to a large extent (Altringham 2011). Since vision is important to both bats and their predators, we briefly summarise some key recent findings relevant to bats' perception of artificial lighting.

Most pteropodids do not echolocate and use vision to locate fruit and flowers. Some echolocating bats use vision to complement auditory information when hunting (Eklöf and Jones 2003) and, if vision and echolocation provide conflicting information, visual information is used in preference (Orbach and Fenton 2010). Vision can also be more effective than echolocation over long distances (Boonman et al. 2013), and the California leaf-nosed bat Macrotus californicus relies more on vision when hunting prey under low levels of illumination equivalent to a moonlit night (Bell 1985).

Recent research on bat vision has focussed on the molecular evolution of lightsensitive pigments (Jones et al. 2013). As for most nocturnal mammals, bat retinas are dominated by rods: they are highly sensitive under low light and confer monochromatic vision. The opsin DNA sequences of rhodopsin (the opsin in rods) were intact in 15 bat species (Zhao et al. 2009a) and wavelengths of maximum absorbance were 497-501 $\mathrm{nm}$.

Colour vision in mammals results in part from opsins in the cones that are sensitive to short and medium wavelengths. Zhao et al. (2009b) sequenced a short-wavelength sensitive opsin gene ( $S w s 1)$ that is most sensitive to blue-violet wavelengths, and a medium-to-long-wavelength sensitive opsin gene $(M / l w s)$ in a range of bat species; maximum absorbance of red light wavelengths by the $M / l w s$ opsin was at 545-553 $\mathrm{nm}$. Although many bats resemble diurnal mammals in having the potential for dichromatic vision, with both genes being intact, $S w s-1$ was pseudogenised in all the rhinolophid and hipposiderid bats studied and in some pteropodids, especially cave-roosting taxa. Immunohistochemistry suggests that 
the primary visual cortex may not respond to stimulation by UV light in these taxa (Xuan et al. 2012a), and behavioural responses to UV were also lacking (Xuan et al. 2012b). The lesser Asiatic yellow bat Scotophilus kuhlii and Leschenault's rousette Rousettus leschenaultii showed behavioural (Xuan et al. 2012b) and immunohistochemical responses in the primary visual cortex (Xuan et al. 2012a) to UV light at $365 \mathrm{~nm}$. Two phyllostomid species (Pallas's long-tongued bat Glossophaga soricina and Seba's short-tailed bat Carollia perspicillata) possess significant cone populations and express opsins that are sensitive to short and long wavelengths. The short-wavelength opsin is sensitive to UV and may be advantageous for the detections of UV-reflecting flowers (Winter et al. 2003; Müller et al. 2009). Other bat species with intact $S w s 1$ genes may be UV sensitive, as ancestral reconstructions suggest UV sensitivity, with maximal sensitivity close to $360 \mathrm{~nm}$ (Zhao et al. 2009b).

Whether differences in UV sensitivity among bat taxa affect how species with intact and pseudogenised $S w s 1$ genes respond to different types of lighting remains unknown. Nevertheless the findings are of interest given that the wavelengths of maximum absorbance in bat opsins lie close to some of the peak emissions of wavelengths in a range of light types (Davies et al. 2013). Moreover emerging LED lighting technologies do not emit UV wavelengths, whereas older technologies, especially HPMV lamps, emit wavelengths that extend into the UV range and so HPMV lights may have been particularly conspicuous to horseshoe bats.

\subsection{Observational Studies on Bats at Street Lights}

Bats have been observed foraging around lights ever since artificial lighting became pervasive (Shields and Bildstein 1979; Belwood and Fullard 1984; Barak and Yom-Tov 1989; Acharya and Fenton 1999). Artificial light attracts many positively phototactic insects (Rydell 1992; Eisenbeis 2006), and most insectivorous bats are probably opportunistic feeders. Thus, they quickly identify and exploit insect accumulations such as swarming termites (Gould 1978) and insect clusters at artificial lights (Fenton and Morris 1976; Bell 1980; de Jong and Ahlén 1991). So some insectivorous bats probably profit from street lights because resource predictability and high insect densities increase foraging efficiency (Rydell 1992, 2006). For instance, 18 of 25 Neotropical insectivorous bat species which could be detected by acoustic monitoring were observed foraging around street lights in a small settlement. While more species were recorded in mature forest, total bat activity was lowest in forest but highest around street lights (Jung and Kalko 2010).

Bats prey on relatively large insects at street lights, mostly moths (Fenton and Morris 1976; Belwood and Fullard 1984; Acharya and Fenton 1992; Acharya 1995; Hickey et al. 1996; Acharya and Fenton 1999; Jacobs 1999; Pavey 1999; Fullard 2001). While moths are the most numerous insects around artificial lights (Huemer et al. 2010; Eisenbeis and Eick 2011), their contribution to a bat's diet can be much higher than expected from their relative abundance at street lights 
(Belwood and Fullard 1984). This implies that bats focus on larger moths rather than smaller prey at street lights. Although moths were only captured in $36 \%$ of attacks, northern bats Eptesicus nilssonii probably gain more than twice as much energy when feeding on moths at street lights than smaller dipterans in woodlands (Rydell 1992).

Aggregations of large insects around lamps enable bats to reduce foraging time and hence energy costs while maximising energy returns (Acharya and Fenton 1999; Jung and Kalko 2010). Big brown bats Eptesicus fuscus, for instance, spend less than half as much time outside the roost where in habitats where they forage at street lights than where they do not use lamps for hunting (Geggie and Fenton 1985). Hence, foraging at lights might be beneficial when a high foraging efficiency compensates for the potentially higher predation risk.

Bat activity and foraging efficiency at street lights are mainly determined by the number and size of prey insects available, both of which are strongly affected by the spectral characteristics of the light (Blake et al. 1994). Thus, the type of light indirectly influences bat activity. The light's attractiveness for insects increases with its UV spectral content. Aerial-hunting long-legged myotis Myotis volans and California myotis $M$. californicus consistently preyed on insects clustered in the cone of experimental black (UV) lights in North America (Bell 1980). While black light is not used for street lighting, similar results are seen with street lights that produce UV emissions. Thus, bat density can be an order of magnitude higher in towns illuminated by HPMV compared with those illuminated by HPS lights and road sections illuminated by HPMV rather than deep-orange LPS lights (Rydell 1992). In Britain, mean bat activity, likely to be mainly common pipistrelles Pipistrellus pipistrellus, is usually equal to or lower along roads lit by LPS lights than in dark sections, whereas bat activity is higher under HPMV than LPS lights or sections with no light (Fig. 7.3; Blake et al. 1994).

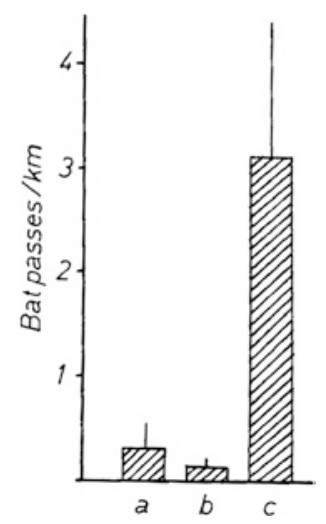

Fig. 7.3 Bat activity varies according to the type of artificial lighting. Activity of pipistrelle Pipistrellus spp. bats (mean and SD) along a $28 \mathrm{~km}$ stretch of road near Aberdeen, Scotland. $a$ rural sections of the road without streetlamps, $b$ village sections with sodium (orange) lamps and $c$ a village with high-pressure mercury vapour lamps. From Rydell and Racey (1995) 


\subsection{Experimental Studies on Bats at Street Lights}

Drawing conclusions from observational studies can be difficult, especially since confounding factors other than the presence of street lights can affect bat activity. Experimental field studies have demonstrated species-specific impacts of street lighting. Two 70 W HPS (DW Windsor Ltd, UK) lights, spaced and orientated to replicate street lights, were installed along preferred commuting routes of lesser horseshoe bats Rhinolophus hipposideros. The commuting activity of R. hipposideros (Fig. 7.4) and Myotis spp. was significantly reduced, and the onset of commuting delayed, on lit nights (Stone et al. 2009; Stone 2011). The following year the experiment was repeated on the same routes using white LED lights (Monaro LED, DW Windsor Ltd), at low (3.6 lux), medium (6.6 lux) and high (49.8 lux) light intensities. Activity of both $R$. hipposideros and Myotis spp. was significantly reduced during all lit treatments, and for $R$. hipposideros, the effect size at 49.8 lux was the same as that under HPS illumination. So both HPS and LED light disturbance caused spatial avoidance of preferred commuting routes by $R$. hipposideros and Myotis spp. (Stone et al. 2009), with no evidence of short-term habituation. Further work is needed to test for long-term habituation. In contrast, there was no significant change in bat activity under HPS and LED light treatments for $P$. pipistrellus, and for bats in the genera Eptesicus and Nyctalus (Fig. 7.5).

$R$. hipposideros and many other slow-flying species rely on linear habitat features for shelter from wind, rain and predators; acoustic orientation; and foraging

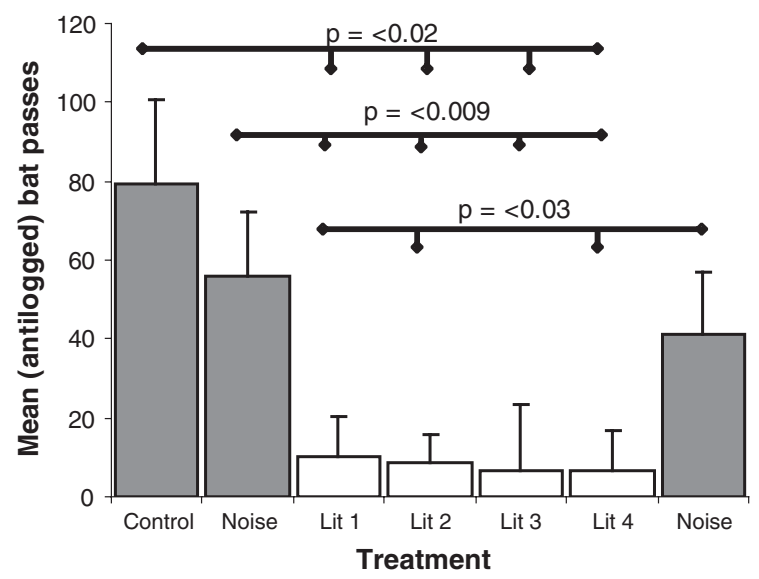

Fig. 7.4 Light-averse bat species show reduced activity along commuting routes subjected to high-pressure sodium (HPS) lighting. Activity of lesser horseshoe bats Rhinolophus hipposideros (mean passes and SE) in relation to lighting treatment. Significant within-subject differences with $p$ values are shown. Treatments were control nights (no lighting treatment or generator), noise controls (HPS light units installed but switched off, generator running at night), 4 nights where lighting was switched on and powered by the generator (Lit 1 to Lit 4) and a final noise control. From Stone et al. (2009) 
(a)

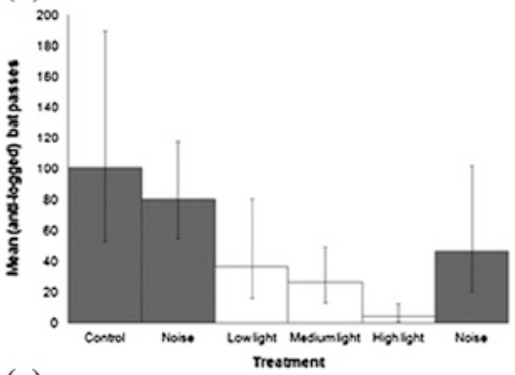

(c)

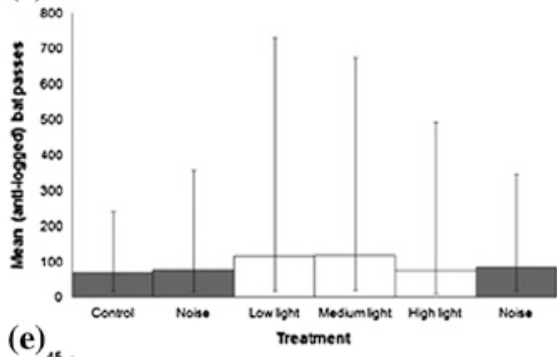

(e) (b)

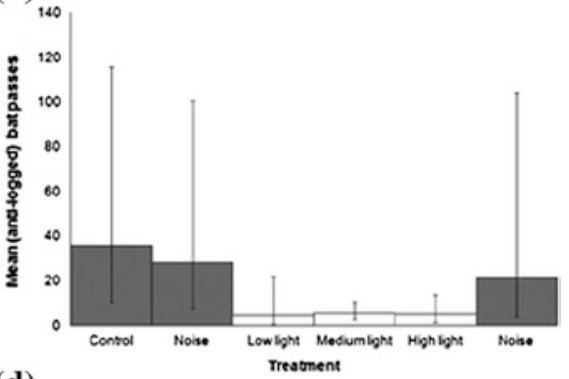

(d) $)_{500}$

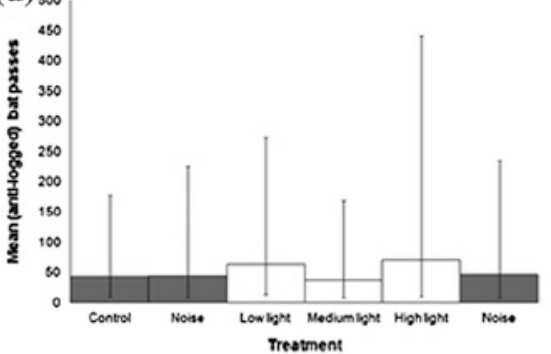

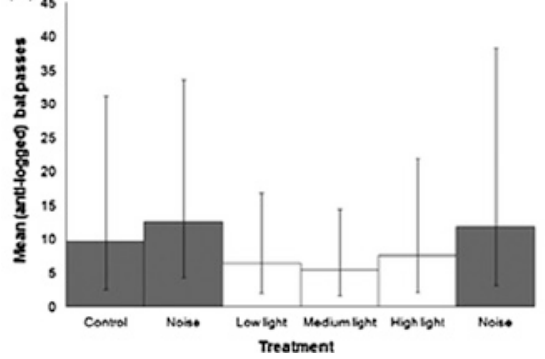

Fig. 7.5 Bats respond in different ways to LED lighting. Although the light-averse Rhinolophus hipposideros showed higher activity under more dimmed treatments compared with less dimmed ones, activity was still less than under unlit conditions. Myotis spp. showed negligible activity under all dimmed treatments. Geometric mean and confidence limits for bat passes along treatment hedges subjected to LED illumination at different light intensities are illustrated. Treatments were control nights (no lighting treatment or generator), noise controls (LED light units installed but switched off, generator running at night), 3 nights where illumination levels were modified (low light mean $=3.6$ lux; medium light mean $=6.6$ lux; and high light mean $=49.8$ lux), and a final noise control. Bat passes were monitored on Anabat bat detectors and are shown for a Rhinolophus hipposideros, b Myotis spp., c common pipistrelle Pipistrellus pipistrellus, $\mathbf{d}$ soprano pipistrelle Pipistrellus pygmaeus and e Nyctalus/Eptesicus. From Stone et al. (2012)

(Verboom and Spoelstra 1999; Verboom et al. 1999). Using suboptimal routes with reduced cover to avoid artificial lighting may increase vulnerability to aerial predators and energetic costs due to increased exposure to wind and rain. So bats may have to travel further to reach foraging areas, reducing foraging time and increasing energetic losses, with consequential negative effects on reproduction rates and fitness. For example, juvenile growth rates were suppressed in the grey bat 
Myotis grisescens with increased travel distance to foraging grounds (Tuttle 1976). Compensating for energetic losses by increasing foraging time may not be possible if, for instance, emergence and/or commuting is delayed by light pollution (Stone et al. 2009). Such delays also increase the risk that bats will miss the dusk peak in insect abundance, reducing the quality of foraging time. Delayed emergence could therefore affect the fitness of both individuals and the roost as whole.

Light disturbance along the commuting routes may isolate bats from their foraging grounds if the energetic costs of using alternative routes exceed the benefits. The commuting costs for $P$. pipistrellus become prohibitive when foraging areas are more than $5 \mathrm{~km}$ from the roost (Speakman 1991). Since bats select roosts based on the quality of surrounding habitat features, including linear connectivity (Jenkins et al. 1998; Oakeley and Jones 1998), maintaining optimal commuting routes is paramount. Whether fitness, or likely proxies of fitness, is affected by lighting needs further evaluation.

\subsection{Winners and Losers: Light-Tolerant and Light-Averse Bats}

Bats show variable responses to light pollution. Insectivorous bats that hunt in open spaces above the canopy (open-space foragers) or along vegetation edges such as forest edges, tree lines or hedgerows (edge foragers) are the species most tolerant of artificial lighting. They have evolved traits advantageous for foraging in sparsely structured habitats (Norberg and Rayner 1987; Neuweiler 1989) and so are preadapted to foraging in urban habitats (Rydell 2006; Jung and Kalko 2010; Jung and Threlfall 2016). Open-space foragers, such as the noctule Nyctalus noctula, typically have long narrow wings with a high aspect ratio, often combined with a high wing loading (weight/wing area). They have to fly fast to remain airborne and so use high-intensity, low-frequency narrowband echolocation calls that facilitate long-range detection of insects (Norberg and Rayner 1987; Rydell 2006; Kalko et al. 2008). When foraging at street lights, open-space foragers typically fly above the lamps, diving into the light cone to catch insects (Jung and Kalko 2010).

Edge foragers generally use echolocation calls with a conspicuous narrowband component, but usually also include a frequency-modulated 'broadband' component during the search phase, which is advantageous for ranging when flying close to obstacles. They comprise relatively fast-flying species with above-average aspect ratio and wing loading (e.g. P. pipistrellus), and species with an average aspect ratio and wing loading (e.g. E. nilssonii). Edge foragers tend to be more manoeuvrable than open-space foragers (Norberg and Rayner 1987; Kalko et al. 2008), and some can even conduct circuits inside the light cone when hunting insects at street lights (Jung and Kalko 2010).

Though most edge foragers fly with agility and speed (Norberg and Rayner 1987), they differ in their degree of synanthropism. While Kuhl's pipistelle 
Pipistrellus kuhlii is recorded almost exclusively at street lights in southern Switzerland, $P$. pipistrellus forage to a similar extent both at lights and at least $100 \mathrm{~m}$ from lights (Haffner and Stutz 1985). Even within a species, foraging activity at lamps can be highly variable depending on the quantity of insects available: Geggie and Fenton (1985) never observed E. fuscus foraging around street lights in an urban environment, whereas in rural habitats feeding activity was greater at lights than in areas without lights. In spring and autumn, when artificial lights attract numerous insects in Sweden, E. nilssonii activity is about 20-fold higher in towns with street lighting than in non-illuminated towns, forest and farmland (de Jong and Ahlén 1991; Rydell 1991), with the bats flying back and forth above the street lights, regularly diving to within $1 \mathrm{~m}$ of the ground to catch insects.

Although fast-flying species adapted to forage in open areas, particularly bats of the genera Eptesicus, Nyctalus and Pipistrellus, may benefit from the increased foraging opportunities provided at lamps that attract high densities of insects, Stone et al. $(2009,2012)$ found no significant increases in bat activity for these 'light-tolerant' species during lit treatments. This could be due to two factors. First, HPS lights are less attractive to insects than white lights because their spectral content has less UV (Blake et al. 1994); for example, HPS street lights attracted fewer insects than white lights in Germany (Eisenbeis and Eick 2011). Second, the experimental nature of the study may have affected the results, since bats may need time to find and recognise newly installed lights as an attractive foraging source.

Though a relatively high proportion of aerial insectivorous bats may forage in suburban habitats, bat activity and the number of bat species decrease significantly towards highly urbanised areas. This is probably because both roosts and appropriate insect habitats are lacking, and those insects which are present might not aggregate at street lamps because the pervasive artificial lighting in city centres causes a dilution effect, rendering the lights less attractive for bats (Gaisler et al. 1998; Avila-Flores and Fenton 2005; Frank 2006; Rydell 2006; Jung and Kalko 2011; Jung and Threlfall 2016). In Panama, 18 of 25 insectivorous bat species frequently foraged around street lamps in a settlement bordering mature forest; the reduced vegetation cover in town constrained strictly forest-dwelling species from hunting at lamps (Jung and Kalko 2010). Yet, even some closely related and ecologically similar species may differ in their tolerance of urban habitats, and their potential to adapt to anthropologically altered habitats is best viewed from a species-specific perspective.

As compared to open-space foragers, bats at the other end of the wing shape spectrum, such as many horseshoe bats (Rhinolophidae) with their low aspect ratio wings and a low wing loading, rarely forage near artificial lights (Rydell 2006; Stone et al. 2009, 2012). They are mostly forest-dwelling and their short broad wings facilitate the high manoeuvrability needed for hawking insects in a cluttered environment (Norberg and Rayner 1987). However, their morphology only allows slow flight speeds, which might render them more vulnerable to predators when flying in a sphere of light away from protective vegetation cover (Jones and Rydell 1994; Rydell et al. 1996). Most forest-dwelling bat species emerge from 
their roosts relatively late in the evening, presumably to minimise predation risk from diurnal birds of prey (Jones and Rydell 1994) and so may be 'hard-wired' to be light-averse. Furthermore, slow-hawking bats use echolocation calls that are adapted for short-range prey detection among clutter (Norberg and Rayner 1987), and so these may not be suitable for orientation in semi-open habitats where most street lights are positioned.

Myotis spp. in Canada and Sweden and brown long-eared bats Plecotus auritus in Sweden were only recorded away from street lights (Furlonger et al. 1987; Rydell 1992). In Australia, the chocolate wattled bat Chalinolobus morio avoided parks when lights were switched on (Scanlon and Petit 2008). Despite having street-lit areas in their home range, they were never utilised by greater horseshoe bats Rhinolophus ferrumequinum (Jones and Morton 1992; Jones et al. 1995). Artificial light reduced the foraging activity of pond bats Myotis dasycneme over rivers in the Netherlands (Kuijper et al. 2008), and commuting activity of $R$. hipposideros and Myotis spp. was reduced under LED and HPS street lights (Stone et al. 2009, 2012). It is likely that the Myotis spp. in Stone et al.'s studies were Natterer's bats Myotis nattereri (Stone 2011). M. nattereri emerges from roosts relatively late (Jones and Rydell 1994), at median light levels (3.5 lux, Swift 1997), lower than those recorded for $R$. hipposideros (Stone et al. 2009). M. nattereri and $R$. hipposideros use different echolocation strategies (Parsons and Jones 2000) but have similar flight and foraging patterns. M. nattereri has broad wings, prefers foraging in woodlands and is slow-flying and manoeuvrable, often foraging close to vegetation to glean prey (Arlettaz 1996; Swift 1997). This suggests that light-dependent predation risk limits the ability of these bats to take advantage of illuminated areas. Nevertheless, one large-eared horseshoe bat Rhinolophus philippinensis was repeatedly observed traversing $200 \mathrm{~m}$ of open grassland to forage extensively around artificial lights in Australia. The same lights were also used by eastern horseshoe bats Rhinolophus megaphyllus (Pavey 1999).

Extinction risk is highest in bat species with low aspect ratios (Jones et al. 2003; Safi and Kerth 2004), which are the species that show aversion to artificial lighting. Thus, species that may suffer most from light pollution are likely to be already threatened taxa.

\subsection{Effects of Light Pollution on Ecosystem Services Provided by Bats}

The impacts of lighting go far beyond changing the physiology, behaviour and/ or distribution of individual species. Since congeners interact with each other as well as their prey and predators, light pollution is likely to have far-reaching consequences for the entire biome and the ecosystem services that bats provide. Insectivorous bats, for instance, significantly reduce the number of insects that cause damage to flora and fauna (Ghanem and Voigt 2012). The value of 
insectivorous bats to the US agricultural industry by reducing insect populations was estimated to be $\$ 23$ billion/year (Boyles et al. 2011).

Most studies to date have been on temperate-zone insectivorous bats. However, many tropical bats feed on nectar and fruits, thereby pollinating flowers and dispersing seeds of several hundred species of plants (Ghanem and Voigt 2012). Consequently, frugivorous bats are key for succession and maintaining plant diversity, especially in fragmented Neotropical landscapes (Medellin and Gaona 1999; Muscarella and Fleming 2007). However, very little is known about the impact of light pollution on this feeding guild. Southern long-nosed bats Leptonycteris yerbabuenae, a nectar- and fruit-eating species, used areas of relatively low light intensity when commuting (Lowery et al. 2009) and Oprea et al. (2009) rarely captured frugivorous bats along roads, although some were present in municipal parks. However, neither study could disentangle the influence of lighting from other factors related to urbanisation, such as altered vegetation cover or increased noise levels. Lewanzik and Voigt (2014) provided the first experimental evidence for light avoidance by frugivorous bats. They found that Sowell's short-tailed bat Carollia sowelli, a specialist on fruits of the genus Piper, harvested only about half as many fruits in a flight cage compartment lit by a sodium vapour street light than in a dark compartment, and free-ranging bats neglected ripe fruits that were experimentally illuminated (Fig. 7.6). Lewanzik and Voigt (2014) concluded that artificial light might reduce nocturnal dispersal of pioneer plant seeds. Since

Fig. 7.6 Artificial lighting reduces and delays feeding behaviour on pepper plants by a frugivorous bat. a Percentage of harvested infructescences of Piper sancti-felices among 14 marked plants harvested by Sowell's short-tailed bats Carollia sowelli in nonilluminated conditions (black) and under conditions where plants were illuminated by a street lamp (grey) in the field, $\mathbf{b}$ time after sunset when infructescences were harvested. From Lewanzik and Voigt (2014)
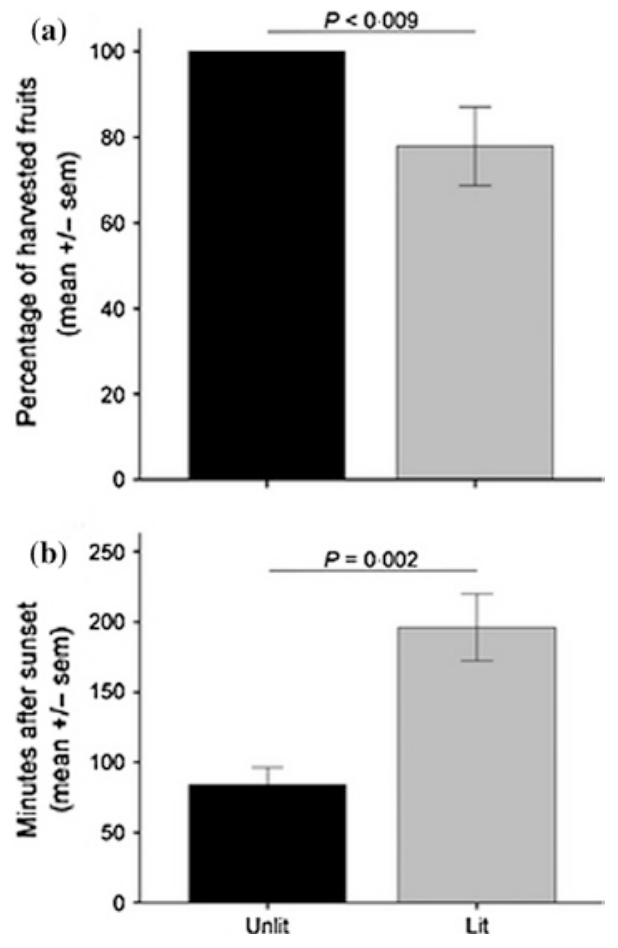
bat-mediated seed intake is particularly important during the early stages of succession (Medellin and Gaona 1999; Muscarella and Fleming 2007), light pollution might slow down the reforestation of cleared rainforests (Lewanzik and Voigt 2014).

\subsection{Knowledge Gaps, Future Challenges and Mitigation Strategies}

\subsubsection{Knowledge Gaps}

Light pollution has only recently been acknowledged as a threat to biodiversity (Hölker et al. 2010b), and there are still many unknowns about the interactions between bat species and artificial lighting sources (Hölker et al. 2010a). Most studies have focused on specific ecological behaviours such as foraging (Rydell 1992; Blake et al. 1994), predator-prey interactions, particularly with moths (Rydell et al. 1995; Svensson and Rydell 1998), commuting routes (Stone et al. 2009, 2012) and roost emergence (Downs et al. 2003). No long-term studies have been carried out to determine whether any of these behavioural changes have fitness consequences (Beier 2006; Stone et al. 2012). The only indication of potential population-level responses has been shown in Hungary on Myotis species, where juveniles roosting in illuminated buildings had a lower body mass than their counterparts in unlit roosts (Boldogh et al. 2007). However, this study did not establish whether a lower body mass in these juveniles reduced their survival rate after hibernation. It is particularly important to understand higher level responses for bat species because they have low fecundity rates, usually only producing one pup per year (Dietz et al. 2009), and so populations are sensitive to sudden changes (Stone et al. 2012).

Further studies are needed to address the impact of artificial lighting at the community level (Davies et al. 2012). The current literature highlights that artificial lighting causes species-specific responses (Rydell 1992; Stone et al. 2009, 2012; Jung and Kalko 2010), which could cause light-tolerant species to exclude light-averse species (Polak et al. 2011; Stone et al. 2012). Such competitive interactions have been proposed as the driving force behind changes in bat populations in Switzerland, where decreases in photosensitive $R$. hipposideros have been linked to increases in light-tolerant P. pipistrellus (Stutz and Haffner 1984; Arlettaz et al. 2000). It is believed that by avoiding street lights, $R$. hipposideros are foregoing profitable prey sources exploited by P. pipistrellus (Arlettaz et al. 1999, 2000).

So far research has focussed largely on insectivorous bats in temperate zones. Further research in tropical ecosystems is needed. For example, the forested areas of South-east Asia contain a high diversity and abundance of horseshoe bat species that are likely to be negatively affected by light pollution, and the impact of light 
pollution on pollination and seed dispersal in the tropics and subtropics needs further investigation.

Research on the impacts of different light spectra in emerging technologies on bat activity and reproduction will be valuable; this is currently being investigated in the Netherlands as part of a large-scale investigation exposing a wide range of taxa to white, red and green LED lighting (see http://www.lichtopnatuur.org). With the current plans to switch to broader spectrum lighting sources, it is important to understand more about the spectral sensitivities of bats (Davies et al. 2012, 2013), especially given the recent findings on opsin genes highlighted above. Determining if there are spectral and intensity thresholds for different species would aid mitigation strategies and improve conservation initiatives (Stone et al. 2012; Gaston et al. 2013).

\subsubsection{Mitigation Strategies}

The most effective approach to reduce the detrimental effects of artificial lighting is to limit the growth of lighting by restricting unnecessary installations or removing them from areas already saturated with artificial lighting sources. This has the greatest potential to reduce light pollution and minimise ecological effects (Gaston et al. 2012). Turning off lights in areas commonly used by light-averse bats to forage, commute or roost during key times such as reproduction (Jones 2000) may be effective. Bats are faithful to maternity roosts due to the specific conditions they provide, and so conserving them is important for maintaining bat populations (Lewis 1995; Mann et al. 2002). However, some photosensitive bats may be disrupted even if areas were only lit for a short period of time (Boldogh et al. 2007), and switching off lighting may be challenged if it is perceived to jeopardise public safety (Lyytimäki and Rinne 2013).

Reducing the duration of illumination through part-night lighting (PNL) schemes could also help limit the adverse effects of light on nocturnal animals (Gaston et al. 2012). This has already been adopted by a number of local authorities in the UK, which switch off lights in specified areas between midnight and 05.30 to reduce $\mathrm{CO}_{2}$ emissions and save money (Lockwood 2011). Since April 2009, lights along sections of motorways have also been switched off between these hours (Royal Commission on Environmental Pollution 2009). While this may help to reduce light pollution, it is unlikely to have significant ecological benefits since the lights remain switched on in the early part of the night, when bats and other nocturnal species undertake key activities such as foraging and commuting (Gaston et al. 2012). Intelligent lighting schemes, such as the use of motion sensors, have already been implemented in Portugal and may have more ecological benefits. The lights remain switched off unless needed and so still provide all the perceived public safety benefits (Royal Commission on Environmental Pollution 2009). However, these fluctuations in lighting levels may also be damaging to bats (Longcore and Rich 2004). 
It is also important to reduce the trespass of artificial lighting to minimise the impact on bats. Newer technologies such as LEDs produce more directional light (Gaston et al. 2012), preventing the horizontal or upward emissions which contribute most to light pollution (Falchi et al. 2011). Effective luminaire design, installation of shielding fixtures and correct column height can also help focus light and avoid wasteful emissions (Royal Commission on Environmental Pollution 2009). In Lombardia, Italy, for example, $75 \%$ of light pollution was due to poorly designed luminaires; the other $25 \%$ was unavoidable reflection from road surfaces (Falchi 2011). Vegetation canopies such as hedgerows can also help decrease light trespass, which is crucial for many bat species that use linear features as commuting routes (Rydell 1992; Fure 2006). Diminishing trespass could create dark refuges, providing corridors for bats to forage in fragmented habitats (Longcore and Rich 2004; Stone et al. 2012; Gaston et al. 2012).

Light intensity has a significant effect on bat activity (Stone et al. 2012) and delays roost emergence (Downs et al. 2003). If bats delay foraging, they risk missing the peak abundance in insects that occurs shortly after dusk, so may not meet their energy requirements, which in turn could reduce fitness (Jones and Rydell 1994; Stone et al. 2012). In addition to implementing PNL, many local authorities are also dimming lights in specified areas (Gaston et al. 2012). This relies on local authorities already having lights such as LEDs that have the necessary centralised management system (International Energy Agency 2006). These schemes are more environmentally friendly and cost-effective (Gaston et al. 2012). However, dimming lights may not be beneficial to all bat species; Daubenton's bats Myotis daubentonii, for instance, only emerge from their roosts at very low light levels (less than 1 lux) (Fure 2006) and R. hipposideros and Myotis spp. avoid commuting routes illuminated to 3.6 lux (Stone et al. 2012). Since illumination levels of street lights are usually between 10 and 60 lux (Gaston et al. 2012), it may not be feasible to dim lighting to such low intensities without compromising public perceptions of safety (Stone et al. 2012; Lyytimäki and Rinne 2013).

\subsubsection{Future Challenges}

With a number of changes to street lighting planned in the coming years, including dimming, PNL and modifications to luminaire design to reduce light pollution, energy expenditure and greenhouse gas emissions, nightscapes could increase in heterogeneity, making it even more challenging to understand the impacts of artificial lighting on biodiversity (Gaston et al. 2012).

This is further complicated because current metrics for measuring emissions from light sources omit key biological information (Longcore and Rich 2004; Gaston et al. 2012). Illumination is measured in lux, which is defined as the brightness of a light according to human spectral sensitivities; spectral sensitivities of other taxa are often very different from ours (Peitsch et al. 1992; Briscoe and Chittka 2001). In bats, for example, many species can detect wavelengths in 
the UV range (Winter et al. 2003; Wang et al. 2004; Müller et al. 2009). So HPS and LPS lamps could have the same intensity of light, e.g. 50 lux, but HPS lamps emit UV wavelengths, whereas LPS lamps do not, thereby affecting both bats and their insect prey in different ways (Longcore and Rich 2004). Since lux is commonly used as a metric by lighting engineers, designers and environmental regulators, migrating from this measure may thwart interdisciplinary communication (Longcore and Rich 2004).

Another challenge is to find more effective ways of quantifying the impact of artificial lighting on bat species. Current methods use acoustic survey methods to quantify bat activity; this underestimates the activity of bats that use low-intensity echolocation calls (O'Farrell and Gannon 1999). Crucially, we also need to determine whether artificial lighting has fitness consequences (Stone et al. 2012). A decrease in bat activity may have no relevance for fitness if, for example, the bats are able to utilise equally suitable alternative sites nearby.

A transdisciplinary approach needs to be adopted to minimise the impact of light on biodiversity, reduce $\mathrm{CO}_{2}$ emissions, increase energy efficiency and reduce costs (Hölker et al. 2010a; Gaston et al. 2012). Scientists, policymakers and engineers need to work together to implement successful strategies (Stone et al. 2012). Moreover, it is vital to find ways to broaden awareness of light pollution and its ecological impacts. Since the public plays an integral part in agreeing mitigation schemes such as dimming lights, their support is pivotal in moving forward (Hölker et al. 2010a).

Acknowledgements EGR, ELS, SH and GJ thank NERC for support. DL was supported by the Federal Ministry for Education and Research (BMBF) as part of the network project 'Loss of the Night'.

Open Access This chapter is distributed under the terms of the Creative Commons Attribution Noncommercial License, which permits any noncommercial use, distribution, and reproduction in any medium, provided the original author(s) and source are credited.

\section{References}

Acharya L (1995) Sex-biased predation on moths by insectivorous bats. Anim Behav 49:1461-1468

Acharya L, Fenton MB (1992) Echolocation behaviour of vespertilionid bats (Lasiurus cinereus and Lasiurus borealis) attacking airborne targets including arctiid moths. Can J Zool 70:1292-1298

Acharya L, Fenton MB (1999) Bat attacks and moth defensive behaviour around street lights. Can J Zool 77:27-33

Altringham JD (2011) Bats: from evolution to conservation, 2nd edn. Oxford University Press, Oxford

Altringham JD, Fenton MB (2003) Sensory ecology and communication in the Chiroptera. In: Kunz TH, Fenton MB (eds) Bat ecology. University of Chicago Press, Chicago, pp 90-127 
Arlettaz R (1996) Foraging behaviour of the gleaning bat Myotis nattereri (Chiroptera, Vespertilionidae) in the Swiss Alps. Mammalia 60:181-186

Arlettaz R, Berthoud G, Desfayes M (1999) Tendances démographiques opposées chez deux espéces sympatriques de chauves-souris, Rhinolophus hipposideros et Pipistrellus pipistrellus: un possible lien de cause à effet? Le Rhinolophe 13:35-41

Arlettaz R, Godat S, Meyer H (2000) Competition for food by expanding pipistrelle bat populations (Pipistrellus pipistrellus) might contribute to the decline of lesser horseshoe bats (Rhinolophus hipposideros). Biol Conserv 93:55-60

Avila-Flores R, Fenton MB (2005) Use of spatial features by foraging insectivorous bats in a large urban landscape. J Mammal 86:1193-1204

Barak Y, Yom-Tov Y (1989) The advantage of group hunting in Kuhl's bat Pipistrellus kuhli (Microchiroptera). J Zool 219:670-675

Bedrosian TA, Fonken LK, Walton JC et al (2011) Chronic exposure to dim light at night suppresses immune responses in Siberian hamsters. Biol Lett 7:468-471

Bedrosian TA, Weil ZM, Nelson RJ (2013) Chronic dim light at night provokes reversible depression-like phenotype: possible role for TNF. Mol Psychiatry 18:930-936

Beier P (2006) Effects of artificial night lighting on terrestrial mammals. In: Rich C, Longcore T (eds) Ecological consequences of artificial night lighting. Island Press, Washington, DC, pp $19-42$

Bell GP (1980) Habitat use and response to patches of prey by desert insectivorous bats. Can J Zool 58:1876-1883

Bell GP (1985) The sensory basis of prey location by the California leaf-nosed bat Macrotus californicus (Chiroptera: Phyllostomidae). Behav Ecol Sociobiol 16:343-347

Belwood JJ, Fullard JH (1984) Echolocation and foraging behaviour in the Hawaiian hoary bat, Lasiurus cinereus semotus. Can J Zool 62:2113-2120

Benenson W, Harris JW, Stocker H et al (2002) Handbook of physics. Prentice Hall, London

Bennie J, Davies TW, Duffy JP et al (2014) Contrasting trends in light pollution across Europe based on satellite observed night time lights. Sci Rep 4(3789):1-6

Berry M, Booth DT, Limpus CJ (2013) Artificial lighting and disrupted sea-finding behaviour in hatchling loggerhead turtles (Caretta caretta) on the Woongarra coast, south-east Queensland, Australia. Aust J Zool 61:137-145

Blake D, Hutson AM, Racey PA et al (1994) Use of lamplit roads by foraging bats in southern England. J Zool 234:453-462

Boldogh S, Dobrosi D, Samu P (2007) The effects of the illumination of buildings on housedwelling bats and its conservation consequences. Acta Chiropterol 9:527-534

Boonman A, Bar-On Y, Cvikel N et al (2013) It's not black or white-on the range of vision and echolocation in echolocating bats. Front Physiol 4. doi:10.3389/fphys.2013.00248

Boyles JG, Cryan PM, McCracken GF et al (2011) Economic importance of bats in agriculture. Science 332:41-42

Briscoe AD, Chittka L (2001) The evolution of color vision in insects. Annu Rev Entomol 46:471-510

Buchanan BW (2006) Observed and potential effects of artificial night lighting on anuran amphibians. In: Rich C, Longcore T (eds) Ecological consequences of artificial night lighting. Island Press, Washington, DC, pp 192-220

California Lighting Technology Centre (2010) 2010 lighting technology overviews and bestpractice solutions. http://cltc.ucdavis.edu/publication/2010-lighting-technology-overview. Accessed 1 June 2014

Campbell N (2011) Biology, 9th edn. Pearson Education, San Francisco

Chemineau P, Malpaux B, Delgadillo JA et al (1992) Control of sheep and goat reproduction: use of light and melatonin. Anim Reprod Sci 30:157-184

Cinzano P, Falchi F, Elvidge CD (2001) The first world atlas of the artificial night sky brightness. Mon Not R Astron Soc 328:689-707

Conrad KF, Warren MS, Fox R et al (2006) Rapid declines of common, widespread British moths provide evidence of an insect biodiversity crisis. Biol Conserv 132:279-291 
Davies TW, Bennie J, Gaston KJ (2012) Street lighting changes the composition of invertebrate communities. Biol Lett 8:764-767

Davies TW, Bennie J, Inger R et al (2013) Artificial light pollution: are shifting spectral signatures changing the balance of species interactions? Glob Change Biol 19:1417-1423

de Jong J, Ahlén I (1991) Factors affecting the distribution pattern of bats in Uppland, central Sweden. Holarctic Ecol 14:92-96

Dietz C, von Helversen O, Nill D (2009) Bats of Britain. Europe and northwest Africa, Black London

Dominoni D, Quetting M, Partecke J (2013) Artificial light at night advances avian reproductive physiology. Proc R Soc Lond B 280:20123017

Dominoni DM, Carmona-Wagner EO, Hofmann M et al (2014) Individual-based measurements of light intensity provide new insights into the effects of artificial light at night on daily rhythms of urban-dwelling songbirds. J Anim Ecol 83:681-692

Douglas RH, Jeffery G (2014) The spectral transmission of ocular media suggests ultraviolet sensitivity is widespread among mammals. Proc R Soc Lond B 281:20132995

Downs NC, Beaton V, Guest J et al (2003) The effects of illuminating the roost entrance on the emergence behaviour of Pipistrellus pygmaeus. Biol Conserv 111:247-252

Eisenbeis G (2006) Artificial night lighting and insects: attraction of insects to streetlamps in a rural setting in Germany. In: Rich C, Longcore T (eds) Ecological consequences of artificial night lighting. Island Press, Washington, DC, pp 281-304

Eisenbeis G, Eick K (2011) Studie zur Anziehung nachtaktiver Insekten an die Straßenbeleuchtung unter Einbeziehung von LEDs. Nat Landsch 86:298-306

Eklöf J (2003) Vision in echolocating bats. Dissertation, University of Göteborg. http://www.fladdermus.net/thesis.htm. Accessed 1 June 2014

Eklöf J, Jones G (2003) Use of vision in prey detection by brown long-eared bats, Plecotus auritus. Anim Behav 66:949-953

Elvidge CD, Keith DM, Tuttle BT et al (2010) Spectral identification of lighting type and character. Sensors 10:3961-3988

Falchi F (2011) Campaign of sky brightness and extinction measurements using a portable CCD camera. Mon Not R Astron Soc 412:33-48

Falchi F, Cinzano P, Elvidge CD et al (2011) Limiting the impact of light pollution on human health, environment and stellar visibility. J Environ Manage 92:2714-2722

Fenton MB, Morris GK (1976) Opportunistic feeding by desert bats (Myotis spp.). Can J Zool 54:526-530

Fonken LK, Nelson RJ (2011) Illuminating the deleterious effects of light at night. F1000 Rep Med 3:18

Fonken LK, Workman JL, Walton JC et al (2010) Light at night increases body mass by shifting the time of food intake. Proc Natl Acad Sci USA 107:18664-18669

Fonken LK, Kitsmiller E, Smale L et al (2012) Dim nighttime light impairs cognition and provokes depressive-like responses in a diurnal rodent. J Biol Rhythm 27:319-327

Frank KD (2006) Effects of artificial night lighting on moths. In: Rich C, Longcore T (eds) Ecological consequences of artificial night lighting. Island Press, Washington, DC, pp 305-344

Frey JK (1993) Nocturnal foraging by scissor-tailed flycatchers under artificial light. Western Birds 24:200

Fullard JH (2001) Auditory sensitivity of Hawaiian moths (Lepidoptera: Noctuidae) and selective predation by the Hawaiian hoary bat (Chiroptera: Lasiurus cinereus semotus). Proc R Soc Lond B 268:1375-1380

Fure A (2006) Bats and lighting. Lond Nat 85:1-20

Furlonger CL, Dewar HJ, Fenton MB (1987) Habitat use by foraging insectivorous bats. Can J Zool 65:284-288

Gaisler J, Zukal J, Rehak Z et al (1998) Habitat preference and flight activity of bats in a city. J Zool 244:439-445 
Gaston KJ, Davies TW, Bennie J et al (2012) Reducing the ecological consequences of nighttime light pollution: options and developments. J Appl Ecol 49:1256-1266

Gaston KJ, Bennie J, Davies TW et al (2013) The ecological impacts of nighttime light pollution: a mechanistic appraisal. Biol Rev 88:912-927

Gauthreaux SA, Belser CG (2006) Effects of artificial night lighting on migrating birds. In: Rich C, Longcore T (eds) Ecological consequences of artificial night lighting. Island Press, Washington, DC, pp 67-93

Geggie JF, Fenton MB (1985) A comparison of foraging by Eptesicus fuscus (Chiroptera: Vespertilionidae) in urban and rural environments. Can J Zool 63:263-267

Ghanem SJ, Voigt CC (2012) Increasing awareness of ecosystem services provided by bats. Adv Stud Behav 44:279-302

Gould E (1978) Opportunistic feeding by tropical bats. Biotropica 10:75-76

Haffner M, Stutz HP (1985) Abundance of Pipistrellus pipistrellus and Pipistrellus kuhlii foraging at street-lamps. Myotis 23:167-172

Haim A, Portnov BA (2013) Light pollution as a new risk factor for human breast and prostate cancers. Springer, Dordrecht

Haim A, Shanas U, Zisapel N et al (2004) Rodent pest control: the use of photoperiod manipulations as a tool. In: Pelz HJ, Cowan DP, Feare CJ (eds) Advances in vertebrate pest management III. Filander, Fürth, pp 29-38

Haim A, Shanas U, Zubidad AES et al (2005) Seasonality and seasons out of time-the thermoregulatory effects of light interference. Chronobiol Int 22:59-66

Hickey MBC, Acharya L, Pennington S (1996) Resource partitioning by two species of vespertilionid bats (Lasiurus cinereus and Lasiurus borealis) feeding around street lights. J Mammal 77:325-334

Hölker F, Moss T, Griefahn B et al (2010a) The dark side of light: a transdisciplinary research agenda for light pollution policy. Ecol Soc 15:13

Hölker F, Wolter C, Perkin EK et al (2010b) Light pollution as a biodiversity threat. Trends Ecol Evol 25:681-682

Holland RA, Thorup K, Vonhof MJ et al (2006) Bat orientation using Earth's magnetic field. Nature 444:702

Huemer P, Kühtreiber H, Tarmann G (2010) Anlockwirkung moderner Leuchtmittel auf nachtaktive Insekten: Ergebnisse einer Feldstudie in Tirol. Tiroler Landesumweltanwaltschaft and Tiroler Landesmuseen Betriebsgesellschaft m.b.H, Innsbruck

International Energy Agency (2006) Light's labour's lost: policies for energy-efficient lighting. http://www.iea.org/publications/freepublications/publication/name,3644,en.html. Accessed 1 June 2014

Jacobs DS (1999) The diet of the insectivorous Hawaiian hoary bat (Lasiurus cinereus semotus) in an open and a cluttered habitat. Can J Zool 77:1603-1608

Jenkins EV, Laine T, Morgan SE et al (1998) Roost selection in the pipistrelle bat, Pipistrellus pipistrellus (Chiroptera: Vespertilionidae), in northeast Scotland. Anim Behav 56:909-917

Jones J (2000) Impacts of lighting on bats. http://www.lbp.org.uk/downloads/Publications/ Management/lighting_and_bats.pdf. Accessed 1 June 2014

Jones G, Morton M (1992) Radio-tracking studies and habitat use by greater horseshoe bats Rhinolophus ferrumequinum. In: Priede IG, Swift SM (eds) Wildlife telemetry, remote monitoring and tracking of animals. Ellis Horwood, Chichester, pp 521-537

Jones G, Rydell J (1994) Foraging strategy and predation risk as factors influencing emergence time in echolocating bats. Phil Trans R Soc Lond B 346:445-455

Jones G, Duvergé PL, Ransome RD (1995) Conservation biology of an endangered species: field studies of greater horseshoe bats. Symp Zool Soc Lond 67:309-324

Jones G, Teeling EC, Rossiter SJ (2013) From the ultrasonic to the infrared: molecular evolution and the sensory biology of bats. Front Physiol 4. doi:10.3389/fphys.2013.00117

Jones KE, Purvis A, Gittleman JL (2003) Biological correlates of extinction risk in bats. Am Nat 161:601-614 
Jung K, Kalko EKV (2010) Where forest meets urbanization: foraging plasticity of aerial insectivorous bats in an anthropogenically altered environment. J Mammal 91:144-153

Jung K, Kalko EKV (2011) Adaptability and vulnerability of high flying Neotropical aerial insectivorous bats to urbanization. Divers Distrib 17:262-274

Jung K, Threlfall CG (2016) Urbanisation and its effects on bats-a global meta-analysis approach. In: Bats in the Anthropocene: conservation of bats in a changing world. Springer International AG, Cham, pp. 13-28

Kalko EKV, Villegas SE, Schmidt M et al (2008) Flying high-assessing the use of the aerosphere by bats. Integr Comp Biol 48:60-73

Kempenaers B, Borgström P, Loës P et al (2010) Artificial night lighting affects dawn song, extra-pair siring success, and lay date in songbirds. Curr Biol 20:1735-1739

Kronfeld-Schor N, Einat H (2012) Circadian rhythms and depression: human psychopathology and animal models. Neuropharmacology 62:101-114

Kuijper DPJ, Schut J, van Dullemen D et al (2008) Experimental evidence of light disturbance along the commuting routes of pond bats (Myotis dasycneme). Lutra 51:37-49

Kyba CCM, Hölker F (2013) Do artificially illuminated skies affect biodiversity in nocturnal landscapes? Landscape Ecol 28:1637-1640

Land MF, Nilsson D-E (2012) Animal eyes, 2nd edn. Oxford University Press, Oxford

Le Tallec T, Perret M, Théry M (2013) Light pollution modifies the expression of daily rhythms and behavior patterns in a nocturnal primate. PLoS ONE 8:e79250

Lewanzik D, Voigt CC (2014) Artificial light puts ecosystem services of frugivorous bats at risk. J Appl Ecol 51:388-394

Lewis SE (1995) Roost fidelity of bats: a review. J Mammal 76:481-496

Lockwood R (2011) A review of local authority road lighting initiatives aimed at reducing costs, carbon emissions and light pollution. https://www.google.co.uk/\#q=review + of + local + auth ority+road+lighting+initiatives. Accessed 1 June 2014

Longcore T, Rich C (2004) Ecological light pollution. Front Ecol Environ 2:191-198

Lowery SF, Blackman ST, Abbate D (2009) Urban movement patterns of lesser long-nosed bats (Leptonycteris curasoae): management implications for the habitat conservation plan within the city of Tucson and the town of Marana. Arizona Game and Fish Department, Phoenix

Lyytimäki J, Rinne J (2013) Voices for the darkness: online survey on public perceptions on light pollution as an environmental problem. J Integr Environ Sci 10:127-139

Mann SL, Steidl RJ, Dalton VM (2002) Effects of cave tours on breeding Myotis velifer. J Wildl Manage 66:618-624

McDonald RI (2008) Global urbanization: can ecologists identify a sustainable way forward? Front Ecol Environ 6:99-104

Medellin RA, Gaona O (1999) Seed dispersal by bats and birds in forest and disturbed habitats of Chiapas, Mexico. Biotropica 31:478-485

Montevecchi WA (2006) Influences of artificial light on marine birds. In: Rich C, Longcore T (eds) Ecological consequences of artificial night lighting. Island Press, Washington, DC, pp 94-113

Müller B, Glösmann M, Peichl L et al (2009) Bat eyes have ultraviolet-sensitive cone photoreceptors. PLoS ONE 4(7):e6390

Muscarella R, Fleming TH (2007) The role of frugivorous bats in tropical forest succession. Biol Rev 82:573-590

Narendran N, Gu Y, Freyssinier JP et al (2004) Solid-state lighting: failure analysis of white LEDs. J Cryst Growth 268:449-456

NASA Earth Observatory/NOAA NGDC (2012) http://eoimages2.gsfc.nasa.gov/images/imagere cords/79000/79765/dnb_land_ocean_ice.2012.3600x1800.jpg. Accessed 1 June 2014

Neuweiler G (1989) Foraging ecology and audition in echolocating bats. Trends Ecol Evol 6:160-166

Norberg UM, Rayner JMV (1987) Ecological morphology and flight in bats (Mammalia; Chiroptera): wing adaptations, flight performance, foraging strategy and echolocation. Phil Trans R Soc Lond B 316:335-427 
Nordt A, Klenke R (2013) Sleepless in town-drivers of the temporal shift in dawn song in urban European blackbirds. PLoS ONE 8(8):e71476

O'Farrell MJ, Gannon WL (1999) A comparison of acoustic versus capture techniques for the inventory of bats. J Mammal 80:24-30

Oakeley SF, Jones G (1998) Habitat around maternity roosts of the $55 \mathrm{kHz}$ phonic type of pipistrelle bats (Pipistrellus pipistrellus). J Zool 245:222-228

Oprea M, Mendes P, Vieira TB et al (2009) Do wooded streets provide connectivity for bats in an urban landscape? Biodivers Conserv 18:2361-2371

Orbach DN, Fenton B (2010) Vision impairs the abilities of bats to avoid colliding with stationary objects. PLoS ONE 5(11):e13912

Parsons S, Jones G (2000) Acoustic identification of twelve species of echolocating bat by discriminant function analysis and artificial neural networks. J Exp Biol 203:2641-2656

Pavey CR (1999) Foraging ecology of the two taxa of large-eared horseshoe bat, Rhinolophus philippinensis, on Cape York Peninsula. Aust Mammal 21:135-138

Peitsch D, Fietz A, Hertel H et al (1992) The spectral input systems of hymenopteran insects and their receptor-based colour vision. J Comp Physiol A 170:23-40

Perry G, Buchanan BW, Fisher RN et al (2008) Effects of artificial night lighting on amphibians and reptiles in urban environments. Herpetol Conserv 3:239-256

Polak T, Korine C, Yair S et al (2011) Differential effects of artificial lighting on flight and foraging behaviour of two sympatric bat species in a desert. J Zool 285:21-27

Poot H, Ens BJ, de Vries H et al (2008) Green light for nocturnally migrating birds. Ecol Soc 13(2):47

Purves D, Lotto RB (2003) Why we see what we do: an empirical theory of vision. Sinauer Associates, Sunderland

Rich C, Longcore T (2006) Ecological consequences of artificial night lighting. Island Press, Washington, DC

Riegel KW (1973) Outdoor lighting is a growing threat to astronomy. Science 179:1285-1291

Royal Commission on Environmental Pollution (2009) Artificial light in the environment. Stationery Office, London

Rydell J (1991) Seasonal use of illuminated areas by foraging northern bats Eptesicus nilssoni. Ecography 14:203-207

Rydell J (1992) Exploitation of insects around streetlamps by bats in Sweden. Funct Ecol 6:744-750

Rydell J (2006) Bats and their insect prey at streetlights. In: Rich C, Longcore T (eds) Ecological consequences of artificial night lighting. Island Press, Washington, DC, pp 43-60

Rydell J, Racey PA (1995) Street lamps and the feeding ecology of insectivorous bats. Symp Zool Soc Lond 67:291-307

Rydell J, Jones G, Waters D (1995) Echolocating bats and hearing moths: who are the winners? Oikos 73:419-424

Rydell J, Entwistle A, Racey PA (1996) Timing of foraging flights of three species of bats in relation to insect activity and predation risk. Oikos 76:243-252

Safi K, Kerth G (2004) A comparative analysis of specialization and extinction risk in temperatezone bats. Conserv Biol 18:1293-1303

Salmon M (2006) Protecting sea turtles from artificial night lighting at Florida's oceanic beaches. In: Rich C, Longcore $\mathrm{T}$ (eds) Ecological consequences of artificial night lighting. Island Press, Washington, DC, pp 141-168

Scanlon AT, Petit S (2008) Effects of site, time, weather and light on urban bat activity and richness: considerations for survey effort. Wildl Res 35:821-834

Schmitz H, Bleckmann H (1998) The photomechanic infrared receptor for the detection of forest fires in the beetle Melanophila acuminata (Coleoptera: Buprestidae). J Comp Physiol A 182:647-657

Schubert EF, Kim JK (2005) Solid-state light sources getting smart. Science 308:1274-1278

Shields WM, Bildstein KL (1979) Birds versus bats: behavioral interactions at a localized food source. Ecology 60:468-474 
Speakman JR (1991) Why do insectivorous bats in Britain not fly in daylight more frequently? Funct Ecol 5:518-524

Spoelstra K, Visser ME (2014) The impact of artificial light on avian ecology. In: Gill D, Brumm $\mathrm{H}$ (eds) Avian urban ecology: behavioural and physiological adaptations. Oxford University Press, Oxford, pp 21-28

Stone EL (2011) Bats and development: with a particular focus on the impacts of artificial lighting. Dissertation, University of Bristol, Bristol

Stone EL, Jones G, Harris S (2009) Street lighting disturbs commuting bats. Curr Biol 19:1123-1127

Stone EL, Jones G, Harris S (2012) Conserving energy at a cost to biodiversity? Impacts of LED lighting on bats. Glob Change Biol 18:2458-2465

Stutz H-PB, Haffner M (1984) Summer colonies of Vespertilio murinus Linnaeus, 1758 (Mammalia: Chiroptera) in Switzerland. Myotis 22:109-112

Suthers RA (1970) Vision, olfaction and taste. In: Wimsatt WA (ed) Biology of bats, vol II. Academic Press, New York, pp 265-281

Svensson AM, Rydell J (1998) Mercury vapour lamps interfere with the bat defence of tympanate moths (Operophtera spp.; Geometridae). Anim Behav 55:223-226

Swift SM (1997) Roosting and foraging behaviour of Natterer's bats (Myotis nattereri) close to the northern border of their distribution. J Zool 242:375-384

The Climate Group (2014) Sydney LED trial: final report. http://www.theclimategroup.org/_ assets/files/Sydney.pdf. Accessed 1 June 2014

Tuttle MD (1976) Population ecology of the gray bat (Myotis grisescens): factors influencing growth and survival of newly volant young. Ecology 57:587-595

Verboom B, Spoelstra K (1999) Effects of food abundance and wind on the use of tree lines by an insectivorous bat, Pipistrellus pipistrellus. Can J Zool 77:1393-1404

Verboom B, Boonman AM, Limpens HJGA (1999) Acoustic perception of landscape elements by the pond bat (Myotis dasycneme). J Zool 248:59-66

Vitousek PM, Mooney HA, Lubchenco J et al (1997) Human domination of earth's ecosystems. Science 277:494-499

Wang D, Oakley T, Mower J et al (2004) Molecular evolution of bat color vision genes. Mol Biol Evol 21:295-302

Winter Y, López J, von Helversen O (2003) Ultraviolet vision in a bat. Nature 425:612-614

Xuan F, Hu K, Zhu T et al (2012a) Immunohisochemical evidence of cone-based ultraviolet vision in divergent bat species and implications for its evolution. Comp Biochem Physiol B 161:398-403

Xuan F, Hu K, Zhu T et al (2012b) Behavioral evidence for cone-based ultraviolet vision in divergent bat species and implications for its evolution. Zoologia 29:109-114

Zhao H, Ru B, Teeling EC et al (2009a) Rhodopsin molecular evolution in mammals inhabiting low light environments. PLoS ONE 4:e8326

Zhao H, Rossiter SJ, Teeling EC et al (2009b) The evolution of color vision in nocturnal mammals. Proc Natl Acad Sci USA 106:8980-8985 